\title{
IASSIST 2007 - CALL FOR PAPERS
}

The theme for the 33rd annual conference of the International Association for Social Science Information Service and Technology (IASSIST) is BUILDING GLOBAL KNOWLEDGE

COMMUNITIES WITH OPEN DATA. We invite your participation on May 16-18, 2007 in Montreal, Quebec, Canada. The conference will be preceded by a day of workshops on May 15 and followed by a weekend of optional activities in the Montreal area. Details about the conference and IASSIST are available at http://www.iassistdata.org

The theme, Building Global Knowledge Communities with Open Data, focuses our attention on the ever increasing globalization of knowledge and the importance of the "open data" concept in the development of knowledge communities. The conference will explore the inter-relationship of knowledge communities with open data. What is required to make data more "open" and available; what are the outcomes from open data; andwhat is the role of the data community in helping this happen?

With this announcement, we seek proposals for papers, sessions, panel discussions, poster/ demonstration sessions and workshops on topics that address all aspects of the conference's theme, including:

* open data and the development of knowledge communities

* the principles of open data

* open data and its implications for documentation, metadata

dissemination, preservation, curation and data authentication

* new data partnerships in knowledge communities

* e-science, cyberinfrastructure and open data

* open data and digital repositories

* developing trusted data repositories in knowledge communities

* open data and issues of confidentiality and disclosure

* the development of statistical literacy in knowledge communities

* developing an agenda for open data literacy

* open spatial data and GIS

* open data and the role of the data librarian

* life cycle models for managing data in knowledge communities

* empirical research results on any of these areas

For other key topics see previous IASSIST Conferences at http://www.iassistdata.org/conferences/index.html

The deadline for these proposals is January 16, 2007. 


\section{|ASSIST 2007}

\section{Procedure}

Individual presentation proposals and session proposals are welcome. Proposals for complete sessions, typically a panel of three to four presentations within a 90-minute session, should provide information on the focus of the session, the organizer or moderator, and possible participants. The session organizer or moderator will be responsible for securing session participants, some of whom may submit paper proposals independently.

Workshops are typically for half a day (3 hours) and may include a hands on component. Proposals should provide an outline of the content the workshop seeks to cover and the names of the presenters

Proposals should include the proposed title, an abstract (limited to 150 words) and 3 to 5 keywords based on the focus of the session.

All proposals (paper, session, poster/demonstration and workshops) can be submitted using the online submission form under Call for Papers on the 2007 Conference site soon to be available via the IASSIST conference webpage, http://www.iassistdata.org/conferences/

Alternatively proposals may be sent via email to <iassist07@gmail.com>. Please use a subject heading of "Paper proposal - Your Name", "Session proposal - Your Name","Poster/Demonstration - Your name" or "Workshop - Your Name" replacing "Your Name" with the name of the author/session etc. organizer.

Following the January 16, 2007 deadline, the Conference Program Committee will send notification of the acceptance of proposals on or before February 15, 2007.

All presenters are required to register and pay the registration fee for the conference. Registration for individual days will be available.

Further information on travel and accommodation will be available shortly from the IASSIST '07 Conference website: http://www.iassistdata.org/conferences/

\section{Online conference registration is scheduled to open in early February, 2007.}

\section{Make plans to come to Montreal for IASSIST 2007 on May 15-18, 2007!}

About IASSIST
IASSIST is an international organization of professionals working in and with information technology and data services to support research and teaching in the social sciences. The organization also explores issues of access, stewardship and the interconnections among social science, behavioral, biological, and health data. Typical workplaces include quantitative and qualitative data archives/libraries, statistical agencies, research centers, libraries, academic departments, government departments, and non-profit organizations. For further information see the IASSIST website at http://www.iassistdata.org.

IASSIST conferences bring together data professionals, data producers, and data analysts from around the world for presentations and workshops covering new and persistent issues relating to access to data, its documentation, and digital preservation, with special emphasis on the social sciences. The social sciences have a

long history of data sharing activity which will make the conference of interest to colleagues in disciplines where improving data access practices is on the policy agenda, and where there are clear overlaps with digital curation, data publishing, e-science/ cyberinfrastructure initiatives, and new interdisciplinary collaborations.

Questions may be sent to the Program Planning Co-Chairs,

Suzette Giles and Louise Corti at iassist07@gmail.com 